\title{
The Role of Young and Future Neurosurgeons in Global Neurosurgery: Perspectives from the Association of Future African Neurosurgeons
}

\author{
Francklin Tetinou ${ }^{1} \quad$ Dylan Djiofack ${ }^{1} \quad$ Nathalie Christelle Ghomsi ${ }^{1} \quad$ Ulrick Sidney Kanmounye
}

${ }^{1}$ Department of Research, Association of Future African

Neurosurgeons, Yaounde, Cameroon

J Neurosci Rural Pract 2020;11:670-670

Each year, 13.8 million patients need neurosurgical interventions, and as many as 5 million do not have access to safe and affordable neurosurgery. ${ }^{1}$ Most of these patients live in low- and middle-income countries (LMICs). Global neurosurgery combines knowledge from operative neurosurgery, neuroepidemiology, and advocacy "with the primary purpose of delivering timely, safe, and affordable neurosurgical care to all who need it."2 Young neurosurgeons can help increase access to care and research.

Most practicing neurosurgeons reside in urban areas, leaving a considerable proportion of the population without access to neurosurgical care. Geographical and financial barriers to care can be solved by integrating neurosurgical procedures to national health insurance schemes and increasing the geographical distribution of neurosurgical providers. ${ }^{3}$ Young neurosurgeons and residents can help practicing neurosurgeons set up and manage local provider networks in underserved communities. Such networks can facilitate the mentorship of young providers by senior neurosurgeons. Together, these two strategies can help improve financial risk protection, reduce referrals to tertiary facilities, and increase access.

Medical students and residents can help manage low-bandwidth online databases of neurosurgical resource availability. These databases can be updated daily by residents or medical students, hosted on free applications like Google Sheets (Google LLC, United States) and KoBo Toolbox (OCHA-HHI-IRC Collaboration) and displayed on a publicly accessible dashboard such as Tableau Public (Salesforce, United States).

LMICs have an enormous neurosurgical workforce deficit. ${ }^{1}$ The Internet, we feel, is an essential tool in the LMIC young neurosurgeon's armamentarium. The online electronic learning model promotes the long-distance acquisition of neurosurgical skills without compromising quality. This model provides a cost-effective solution to learning, but its most significant challenge is sustainability. ${ }^{4}$ eBrain, Neurosurgical Atlas, Upsurgeon, and Touch Surgery are a few examples of sustainable e-learning platforms. Young neurosurgeons and
Address for correspondence Ulrick Sidney Kanmounye, MD, 170 Washington Street, Malden, MA 02148, United States (e-mail: ulricksidney@gmail.com).

residents should participate in the design, sessions, and evaluations of these platforms. Also, the neurosurgical community should encourage medical students to choose a neurosurgery career. Faculty and residents should mentor students and help them develop skills for residency.

LMICs need evidence-based practice guidelines developed from quality local research. Building the research capacity of young neurosurgeons and residents will help increase the number and experience of local researchers. Young neurosurgeons and residents should equally disseminate their study findings scientifically (manuscripts, abstracts, and presentations) and through nonscientific communication (op-eds, social media, and television).

Young neurosurgeons and residents have an essential role to play in global neurosurgery and they should be supported.

\section{Funding}

None.

\section{Conflict of Interest}

None declared.

\section{References}

1 Dewan MC, Rattani A, Fieggen G, et al. Global neurosurgery: the current capacity and deficit in the provision of essential neurosurgical care. Executive summary of the Global Neurosurgery Initiative at the Program in Global Surgery and Social Change. J Neurosurg 2018;130(4):1039-1408

2 Park K WFNS Global Neurosurgery Committee. Global Neurosurgery. Published November 4, 2019. Available at: https://globalneurosurgery.org/. Accessed January 3, 2020

3 Robertson FC, Esene IN, Kolias AG, et al; Global Neurosurgery Survey Collaborators. Global perspectives on task shifting and task sharing in neurosurgery. World Neurosurg $\mathrm{X}$ 2019;6:100060

4 Liang KE, Bernstein I, Kato Y, Kawase T, Hodaie M. Enhancing neurosurgical education in low- and middle-income countries: current methods and new advances. Neurol Med Chir (Tokyo) 2016;56(11):709-715 